\title{
The Application of a Three-Step Serum Proteome Analysis for the Discovery and Identification of Novel Biomarkers of Hepatocellular Carcinoma
}

\author{
Asako Kimura, ${ }^{1}$ Kazuyuki Sogawa, ${ }^{2}$ Mamoru Satoh, ${ }^{1}$ Yoshio Kodera, ${ }^{2,3}$ Osamu Yokosuka, ${ }^{4}$ \\ Takeshi Tomonaga, ${ }^{1,5}$ and Fumio Nomura ${ }^{1,2}$
}

${ }^{1}$ Department of Molercular Diagnosis, Graduate School of Medicine, Chiba University, Chiba 260-0856, Japan

${ }^{2}$ Clinical Proteomics Research Center, Chiba University Hospital, Chiba, Japan

${ }^{3}$ Laboratory of Biomolecular Dynamics, Department of Physics, Kitasato University School of Science, Kanagawa, Japan

${ }^{4}$ Department of Medicine and Clinical Oncology, Graduate School of Medicine, Chiba University, Chiba 260-0856, Japan

${ }^{5}$ Laboratory of Proteome Research, National Institute of Biomedical Innovation, Osaka, Japan

Correspondence should be addressed to Fumio Nomura, fnomura@faculty.chiba-u.jp

Received 7 February 2012; Accepted 5 June 2012

Academic Editor: Dayan B. Goodenowe

Copyright () 2012 Asako Kimura et al. This is an open access article distributed under the Creative Commons Attribution License, which permits unrestricted use, distribution, and reproduction in any medium, provided the original work is properly cited.

The representative tumor markers for HCC, AFP, and PIVKA-II are not satisfactory in terms of sensitivity and specificity in the early diagnosis of HCC. In search for novel markers for HCC, three-step proteome analyses were carried out in serum samples obtained from 12 patients with HCC and 10 with LC. As a first step, serum samples were subjected to antibody-based immunoaffinity column system that simultaneously removes twelve of abundant serum proteins. The concentrated flow-through was then fractionated using reversed-phase HPLC. Proteins obtained in each fraction were separated by SDS-PAGE. Serum samples obtained from patient with HCC and with LC were analyzed in parallel and their protein expression patterns were compared. A total of 83 protein bands were found to be upregulated in HCC serum. All the protein bands, the intensity of which was different between HCC and LC groups, were identified. Among them, clusterin was most significantly overexpressed $(P=0.023)$. The overexpression of serum clusterin was confirmed by ELISA using another validation set of HCC samples. Furthermore, serum clusterin was elevated in $40 \%$ of HCC cases in which both AFP and PIVKA-II were within their cut-off values. These results suggested that clusterin is a potential novel serum marker for HCC.

\section{Introduction}

Hepatocellular carcinoma (HCC) is one of the most common cancers in the world and is a leading cause of death in many countries. Chronic infection by hepatitis B virus (HBV) or hepatitis C virus (HCV) and cirrhosis are major risk factors for HCC development $[1,2]$. At present, HCC surveillance with tumor markers and imaging studies such as ultrasonography (US), computed tomography (CT), and magnetic resonance imaging (MRI) have been recommended for patients with cirrhosis $[3,4]$. These imaging studies are expensive and the ultrasound is highly dependent on the ability of the operator. Therefore, more sensitive and specific serum biomarkers for early detection of HCC are desirable.
Serum tumor markers for detecting HCC could be divided into 4 categories: oncofetal and glycoprotein antigens, enzymes and isoenzymes, genes, and cytokines. Alpha-fetoprotein (AFP) and protein induced by vitamin-K absence or antagonist-II (PIVKA-II) also called des-gammacarboxyprothrombin (DCP) are representative tumor markers for the diagnosis of HCC.

The elevated level of AFP is observed in only $50-70 \%$ of patients with HCC and also frequently in patients with cirrhosis or exacerbations of chronic hepatitis [5], and its sensitivity is low in patients with earlier/small tumors [68]. Measurement of lectin lens culinaris agglutinin (LCA) bound fraction of AFP (AFP-L3) can improve the specificity of AFP. Elevated DCP activity was only present in $28-47.6 \%$ 
of HCCs of less than $3 \mathrm{~cm}$ in size [9-11]. Therefore, there has been growing interest and need to develop novel HCC serum biomarkers with greater sensitivity and specificity. Recent studies indicate that some other tumor markers, such as glypican 3 [12-17], gamma-glutamyl transferase II [18], alpha-1-fucosidase [19, 20], vascular endothelial growth factor [21-23], and transforming growth factor-beta $1[24,25]$ could serve as a complementary marker for AFP. Furthermore, the circulating genetic markers such as AFPmRNA $[26,27]$ and human telomerase reverse transcriptase mRNA [28, 29] have been shown to be diagnostic and prognostic indicators of HCC.

Proteomics is the systematic study of proteomes, which describes the complete set or proteins found in a given cell type as well as of body fluids such as serum and urine. Recent advances in sophisticated technologies in proteomics should provide promising ways to discover novel markers in various fields of clinical medicine.

Increasing number of recent reports provide evidence that proteomic approach is promising tools to discover and identify novel biomarker for HCC. In particular, surfaceenhanced laser desorption/ionization time-of-flight mass spectrometry (SELDI-TOF MS) is a representative example of a proteomics technique for the high-throughput fingerprinting of serum proteins and peptides [30]. We used the SELDI technology to generate comparative protein profiles of consecutive serum samples obtained during abstinence from alcoholic patients and found some novel biomarker for excessive alcohol consumption [31, 32]. Using this technique, several protein peaks leading to differentiation of patients with HCC from patients with cirrhosis alone have been discovered $[33,34]$. In these studies, crude serum samples were directly analyzed without particular preanalytical preparations. The technical challenge in the analysis of serum proteome is that serum proteins are present at unequal concentrations. Indeed, 22 of the most abundant proteins account for $>99 \%$ of total serum proteins [35], which hampers the detection of thousands of other low abundance proteins and peptides.

To detect the disease-associated proteins present in low abundance using currently available methods, the most abundant proteins have to be removed first by technique such as immunodepletion. We recently developed a three-step serum proteome analysis involving removal of 12 abundant proteins and subsequent reversed-phase high-performance liquid chromatography fractionation and one-dimensional electrophoresis and identified three proteins including YKL50 as a promising biomarker of sepsis [36]. More recently, using this method, we identified promising biomarkers for alcohol abuse [37], breast cancer [38], and pancreatic cancer [39].

In this study, we applied this three-step proteome analysis to find novel biomarkers of HCC.

\section{Material and Methods}

2.1. Patients and Serum Samples. As an initial set of samples, blood samples of $12 \mathrm{HCV}$-related HCC patients and 10
HCV-related LC patients obtained at the Department of Medicine and Clinical Oncology, Chiba University Hospital, were used for comprehensive proteome analysis. All patients were positive for hepatitis $\mathrm{C}$ antibodies on the day of sampling and were diagnosed pathologically or clinically.

Diagnostic values of marker candidates identified in the initial set of samples were further validated using another set of samples. For this purpose, serum sample sets of $64 \mathrm{HCV}$ related HCC and $60 \mathrm{HCV}$-related LC patients were obtained from Chiba University Hospital and 60 healthy individuals for normal control from Kashiwado Clinic in Port-Square of Kashiwado Memorial Foundation, Chiba. These healthy individuals were defined in this study as subjects without medication on a regular basis, obesity, heavy drinking, abnormal liver test results, and hepatitis virus carriage.

Written informed consent was obtained from all patients. Serum samples were obtained and processed under the standardized conditions as we reported elsewhere [40] and were stored as aliquots at $-80^{\circ} \mathrm{C}$ until analysis.

The clinical characteristics of all the patients are shown in Tables 1 and 2 .

\subsection{Immunoaffinity Depletion of High-Abundant Proteins} from Human Serum. The outline of our experimental procedures is summarized in Figure 1. For removal of the twelve most abundant proteins: albumin, IgG, transferrin, fibrinogen, IgA, aplha2-macroglobrin, IgM, aplha1-antitrypsin, haptoglobin, aplha1-acidglycoprotein, apolipoprotein A-I, and apolipoprotein A-II, Proteome Lab IgY-12HC LC10 column (Beckman coulter Inc., Fullerton, CA, USA) was used. According to the manufacturer's instructions, $100 \mu \mathrm{L}$ of each serum was diluted 5-fold with buffer A (dilution buffer) and injected onto the column in $100 \%$ buffer A at a flow rate of $0.5 \mathrm{~mL} / \mathrm{min}$ for $25.0 \mathrm{~min}$ and $2.0 \mathrm{~mL} / \mathrm{min}$ for $5.0 \mathrm{~min}$ on a Shimadzu LC10A VP system (Shimadzu Co., Kyoto, Japan). After collection of the flow-through fraction containing unbound proteins, the column was washed and the bound proteins were eluted with $100 \%$ buffer B (stripping buffer) at a flow rate of $2.0 \mathrm{~mL} / \mathrm{min}$ for $18.0 \mathrm{~min}$.

The chromatograms were monitored at $280 \mathrm{~nm}$ and 8 fractions (flow-through) were collected at $0.5 \mathrm{~min}$ intervals from 12.1 to $20.0 \mathrm{~min}$. The fractions were collected into $1.5 \mathrm{~mL}$ microcentrifuge tubes.

\subsection{Concentrating of Fractions by Centrifugal Ultrafiltration.} The flow-through fractions (total $4.0 \mathrm{~mL}$ ) were applied to Vivaspin 2 spin concentrators (MWCO 10 KD, Vivascience, Hannover, Germany) and concentrated to a volume of $80 \mu \mathrm{L}$ according to the manufacturer's instructions. The concentrated pool was stored at $-80^{\circ} \mathrm{C}$ until use.

\subsection{HPLC Sample Preparation, Separation, and Fraction} Collection. HPLC separations were performed on an automated SHISEIDO NANOSPACE SI-2 system (Shiseido Fine Chemicals, Tokyo, Japan). Injection was performed by an autosampler with a completely filled $100 \mu \mathrm{L}$ injection loop. $75 \mu \mathrm{L}$ of concentrated flow-through samples were directly loaded onto the Intrada WP-RP column (Imtakt, Kyoto, 
TABLE 1: Clinical characteristics of the $12 \mathrm{HCC}$ (a) and $10 \mathrm{LC} \mathrm{(b)} \mathrm{patients.}$

(a)

\begin{tabular}{lcccccccc}
\hline Case number & Sex & Age & Stage & Child-Pugh & Tumor size $(\mathrm{mm})$ & Differentiation & AFP $(\mathrm{ng} / \mathrm{mL})$ & PIVKA-II $(\mathrm{mAU} / \mathrm{mL})$ \\
\hline H1 & M & 71 & III & A & Multiple, max 30 & Poorly & 70.6 & 18 \\
H2 & M & 73 & IV & B & Multiple, max 50 & Moderately & 549.6 & 44 \\
H3 & F & 69 & III & A & 38 & Moderately-well & 11.9 & 59 \\
H4 & M & 73 & III & B & $32-30$ & Moderately & 208.1 & 20 \\
H5 & M & 69 & III & B & $29-25$ & Moderately-well & 38.3 & 12 \\
H6 & F & 77 & III & A & Multiple, max30 & Moderately-well & 47.3 & 10 \\
H7 & M & 67 & III & A & $30-10$ & Moderately & 14.9 & 35 \\
H8 & F & 71 & III & B & $35-20$ & Well & 1031.7 & 466 \\
H9 & M & 58 & IV & B & 20 & Moderately & 25.1 & 75 \\
H10 & F & 71 & III & B & 30 & Poorly-moderately & 14640 & $<10$ \\
H11 & M & 81 & III & A & 25 & Moderately & 62.3 & 6854 \\
H12 & M & 70 & III & A & 60 & - & 1390 & 5350 \\
\hline
\end{tabular}

(b)

\begin{tabular}{|c|c|c|c|c|c|}
\hline Case number & Sex & Age & Child-Pugh & AFP (ng/mL) & PIVKA-II (mAU/mL) \\
\hline L1 & $\mathrm{M}$ & 45 & B & 12 & - \\
\hline $\mathrm{L} 2$ & $\mathrm{~F}$ & 54 & A & 36.4 & $<10$ \\
\hline L3 & M & 59 & A & 24.3 & 31 \\
\hline L4 & M & 59 & B & 12.8 & 66 \\
\hline L5 & $\mathrm{F}$ & 62 & A & 4.5 & - \\
\hline L6 & M & 43 & A & 8.5 & - \\
\hline L7 & M & 48 & B & 11.3 & - \\
\hline L8 & M & 60 & A & 37.7 & - \\
\hline L9 & $\mathrm{F}$ & 68 & A & 15.3 & - \\
\hline L10 & $\mathrm{M}$ & 45 & B & 6 & - \\
\hline
\end{tabular}

TABLe 2: Clinical characteristics of 64 patients with HCC, 60 with LC and 60 normal control subjects.

\begin{tabular}{lccc}
\hline & HCC & LC & Normal control \\
\hline & $n=64$ & $n=60$ & $n=60$ \\
Age, mean \pm SD & $66.1 \pm 9.9$ & $56.8 \pm 12.3$ & $54.5 \pm 7.0$ \\
Male/female & 7.0 & 6.5 & 6.5 \\
AFP level $(\mathrm{ng} / \mathrm{mL})$, mean \pm SD & $1926.2 \pm 11904.7$ & $14.7 \pm 24.2$ & $3.5 \pm 1.6$ \\
PIVKA-II level $(\mathrm{mAu} / \mathrm{mL})$, mean \pm SD & $11757.2 \pm 50071.5$ & $18.1 \pm 12.5$ & $19.71 \pm 5.4$ \\
\hline
\end{tabular}

Japan). The RP separations for each flow-through were performed under a set of conditions using a multisegment elution gradient, with eluent A $(0.1 \%$ TFA in water, v/v) and eluent B $(0.08 \%$ TFA in $90 \%$ acetonitrile, v/v). The gradient conditions consisted of three steps with increasing concentrations of the eluent B: 5\% B 5 min, 5-95\% B 23 min, $95 \%$ B $11 \mathrm{~min}$, and 5\% B $21 \mathrm{~min}$ for reequilibration of the column, at a flow rate of $0.40 \mathrm{~mL} / \mathrm{min}$ for a total runtime of $60 \mathrm{~min}$.

The chromatograms were monitored at $218 \mathrm{~nm}$ and 40 fractions were collected at $0.5 \mathrm{~min}$ intervals from 19.1 to $39.1 \mathrm{~min}$. Each fraction was dried in a centrifugal vacuum concentrator and stored at $-80^{\circ} \mathrm{C}$ for subsequent SDS-PAGE analysis.

2.5. Electrophoretic Analysis. Dried fraction samples from HPLC separations were dissolved in $15 \mu \mathrm{L}$ of sample preparation buffer, vortexed, and then loaded onto the two
Perfect NT Gels (10-20\% acrylamide, 20 wells, $140 \mathrm{~mm} \times$ $140 \mathrm{~mm} \times 1 \mathrm{~mm}$; DRC. Co., Ltd.).

SDS-PAGE analysis was carried out by an established method [41]. Following electrophoresis, proteins were visualized by silver staining using 2D silver stain II "DAIICHI" (Daiichi Pure Chemicals Co., Ltd., Osaka, Japan).

2.6. In-Gel Digestion. For protein identification, samples were prepared again as described above. To obtain high sensitivity, the same process was repeated three times per sample; finally dried fraction sample of triple amount were obtained. $45 \mu \mathrm{L}$ of combined dried fraction samples were loaded on to SDS-PAGE gel as described above after these samples were individually dissolved with $15 \mu \mathrm{L}$ sample buffer.

After then, protein spots in Coomassie brilliant blue $(\mathrm{CBB})$ stained SDS-PAGE gels were individually excised in squares of about 1 to $2 \mathrm{~mm}$ per side destained in $50 \%$ $\mathrm{v} / \mathrm{v}$ acetonitrile/50 $\mathrm{mM} \mathrm{NH}_{4} \mathrm{HCO}_{3}$ and then washed with 


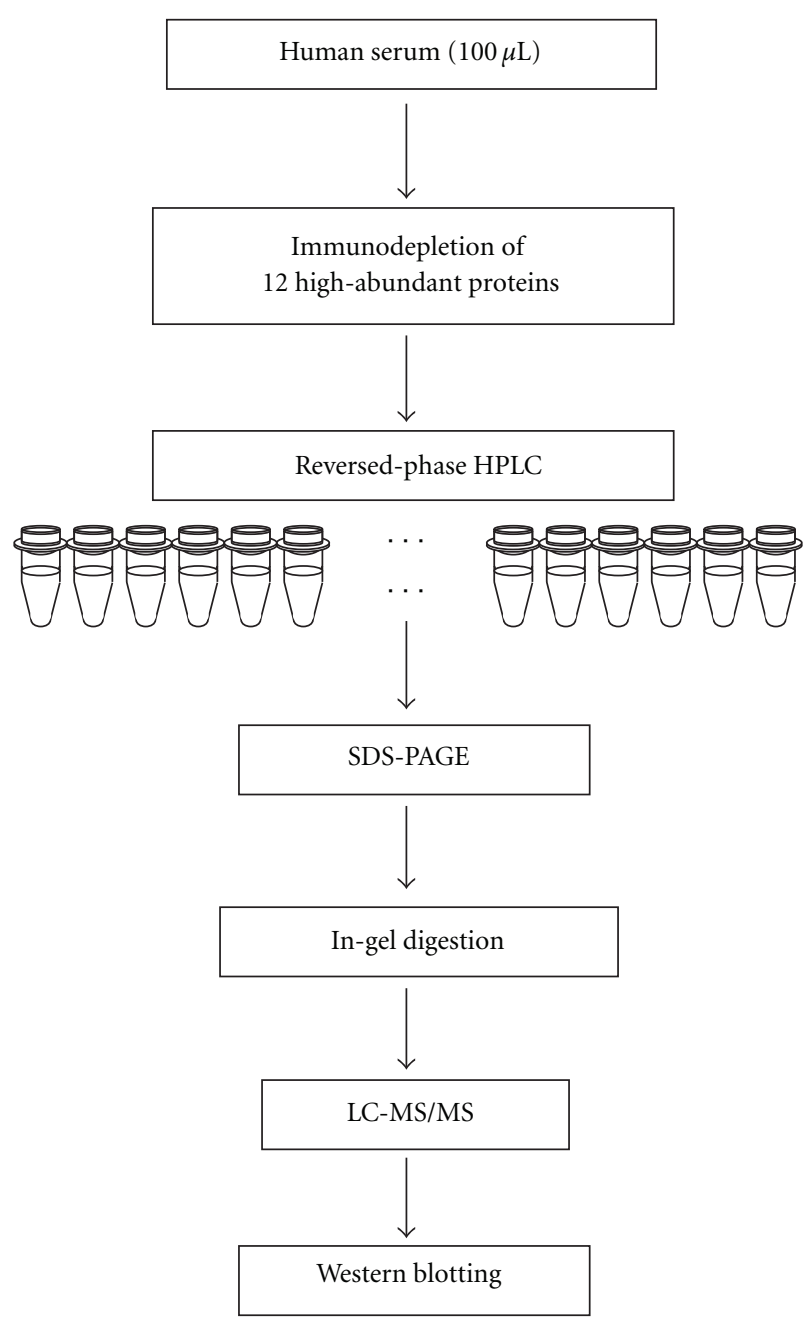

Figure 1: Schematic diagram of the experimental protocol.

deionized water. The gel pieces were dehydrated in 100\% acetonitrile for about $15 \mathrm{~min}$ and then dried in a SpeedVac Evaporator (Wakenyaku, Kyoto, Japan) for $60 \mathrm{~min}$. The pieces were rehydrated in $10-20 \mu \mathrm{L}$ of $25 \mathrm{mM}$ Tris- $\mathrm{Cl}$ ( $\mathrm{pH}$ 9.0) containing $25 \mathrm{ng} / \mu \mathrm{L}$ trypsin (Trypsin sequence grade, Roche, Mannheim, Germany) for $45 \mathrm{~min}$ at $4^{\circ} \mathrm{C}$. After removal of excess trypsin, the gel pieces were incubated in a minimal volume $(10-20 \mu \mathrm{L})$ of $50 \mathrm{mM}$ Tris ( $\mathrm{pH} 9.0)$ buffer for $24 \mathrm{~h}$ at $37^{\circ} \mathrm{C}$. The solution containing digested fragments of proteins was transferred to $1.5 \mathrm{~mL}$ siliconized plastic test tube and stored at $4^{\circ} \mathrm{C}$. Peptide fragments remaining in gel pieces were further recovered after $20 \mathrm{~min}$ incubations at room temperature in minimal volumes of $5 \% \mathrm{v} / \mathrm{v}$ formic acid containing 50\% v/v acetonitrile. The solutions containing peptides were pooled together in the tube at $4^{\circ} \mathrm{C}$.

2.7. LC-MS/MS. Molar quantities of recovered peptide fragments were estimated from the staining intensity of the SDS-PAGE bands that were digested in-gel with trypsin. Digested peptides equivalent to the maximum of $10 \mathrm{pmoL}$ of a protein in an SDS-PAGE band were injected into a Magic
C18 column (Michrom Bioresources, Inc., CA, USA), which was attached to the MAGIC 2002 (Michrom Bioresources, Inc., CA, USA) high-performance liquid chromatography (HPLC) system. The flow rate of the mobile phase was $1 \mu \mathrm{L} / \mathrm{min}$ using MAGIC Variable Splitter. The solvent composition of the mobile phase was programmed to change in 50 min cycles with varying mixing ratios of solvent $\mathrm{A}(2 \%$ $\mathrm{v} / \mathrm{v} \mathrm{CH}_{3} \mathrm{CN}$ and $\left.0.1 \% \mathrm{v} / \mathrm{v} \mathrm{HCOOH}\right)$ to solvent $\mathrm{B}(90 \% \mathrm{v} / \mathrm{v}$ $\mathrm{CH}_{3} \mathrm{CN}$ and $\left.0.1 \% \mathrm{v} / \mathrm{v} \mathrm{HCOOH}\right)$. Next, the peptides were eluted with a linear gradient from 0 to $50 \%$ solvent B. Purified peptides were introduced from HPLC to Q-star (Applied Biosystems, Foster City, CA, USA), a hybrid quadrupole time-of-flight mass spectrometer, via an attached FortisTip (AMR, Tokyo, Japan). Mascot search engine (Matrixscience, London, UK) was used to identify proteins from the mass and tandem mass spectra of peptides. Peptide mass data were matched by searching the National Center for Biotechnology Information database using MASCOT engine (http://www.matrixscience.com/). The minimum criterion of the probability-based MASCOT/MOWSE score was set with $5 \%$ as the significant threshold level.

2.8. Western Blot Analysis. After the 12 abundant proteins were removed from serum as described above, the depleted samples were separated on SDS-polyacrylamide gel electrophoresis $(80 \times 40 \times 1.0 \mathrm{~mm}, 10-20 \%$ polyacrylamide gradient gel, $240 \mathrm{~V})$ and transferred to a methanol-rinsed polyvinyl-difluoride (PVDF) membrane $(0.45 \mu \mathrm{m}$ pore size in roll form, Millipore, Bedford, MA) (Amersham, HybondC Extra Supported) $(40 \mathrm{~V}, 25 \mathrm{~min})$ using the XV Pantera System (DRC Co., Ltd., Tama, Japan). After transferring the proteins to a membrane and blocking with 5\% skim milk in phosphate-buffered saline (PBS) for $1 \mathrm{~h}$ at room temperature, the membranes were incubated at $4{ }^{\circ} \mathrm{C}$ overnight with the primary antibody to clusterin $(1: 3000$, mouse monoclonal, upstate (now part of Millipore), CA, USA). The membrane was washed for a total $30 \mathrm{~min}$ in 3 changes of PBS-Tween $(0.1 \%)$ prior to incubation in the appropriate horseradish peroxidase-linked secondary antibody (anti-mouse IgG horseradish peroxidase-linked secondary antiserum, 1:500) for $1 \mathrm{~h}$ at room temperature. The membranes were finally washed three times as previously described, and immunoreactive proteins were revealed with an enhanced chemiluminescence substrate reaction using ECL western blotting detection reagents (GE Healthcare UK Ltd., Amersham, England) according to the manufacturer's instructions.

2.9. Gel Imaging and Analysis. The Silver-stained SDS-gels and CBB-stained gels were scanned with an optical resolution of 400 dpi by EPSON ES-2000 scanner (SEIKO EPSON Corp., Nagano, Japan) using EPSON TWAIN Pro software (SEIKO EPSON Corp., Nagano, Japan). The images were processed using Photoshop 6 (Adobe) software. After scanning, each gel was stored at $4^{\circ} \mathrm{C}$.

TIFF files of the gel images were transferred for analysis with a TotalLab TL120 (Nonlinear Dynamics Ltd., Newcastle, UK) and were used for band detection and statistical analysis. 
2.10. Measurement of Serum Clusterin Concentration by ELISA. Serum clusterin was quantified using a human clusterin ELISA kit (R\&D systems, Inc., MN, USA) following manufacturer's instructions. Human clusterin standard as provided in the kit $(1,000 \mathrm{ng} / \mathrm{mL}$ : stock solution), and the serially diluted standards (200-3.12 ng/mL) were prepared from the stock solution. Calibrator Diluent RD5T (dilution buffer) serves as the blank. Test serum samples were diluted $1: 2000$ in the dilution buffer.

After adding $100 \mu \mathrm{L}$ of Assay Diluent RD1-19 to each well, $50 \mu \mathrm{L}$ aliquots of the standards and diluted test samples were added in duplicate to the wells of a microtiter plate coated with antihuman clusterin antibody.

After incubation at room temperature for 2 hours on a horizontal orbital shaker, the plate was washed using $400 \mu \mathrm{L}$ of Wash Buffer and repeated three time processes and a total of four washes. After the last wash, $200 \mu \mathrm{L}$ of antihuman clusterin monoclonal antibody conjugated to horseradish peroxidase was added to the wells. The plate was incubated for 2 hours at room temperature on the shaker, followed by washes as before and addition of $200 \mu \mathrm{L}$ of substrate solution containing hydrogen peroxide and tetramethylbenzidine to the wells. The plate was stetted at the dark to protect from light and incubated for $30 \mathrm{~min}$ at room temperature to allow for color development. The reaction was stopped by the addition of $50 \mu \mathrm{L}$ of stop solution, and the optical densities were determined by reading absorbance at $450 \mathrm{~nm}$ with iMark Microplate Reader (Bio-Rad Laboratories, Inc., CA, USA).

2.11. Other Procedures. Numerical data were presented as mean \pm SD. Statistical significance of difference was assessed by Student's $t$-test; $P$ values less than 0.05 were considered significant.

Serum AFP and PIVKA-II levels were determined by commercially available assay kits.

\section{Results}

3.1. Immunoaffinity Serum Depletion. Schematic diagram of our experimental protocol is summarized in Figure 1.

Figure 2 is a representative immunoaffinity chromatogram and shows a substantial removal of high-abundant proteins from a human serum sample. The immunodepletion of the high-abundant serum proteins was conducted in a reproducible manner in samples obtained from seven HCC and five LC patients (data not shown). A total of $4 \mathrm{~mL}$ of flow-through fractions were collected, desalted, and concentrated prior to reversed-phase HPLC.

3.2. RP-HPLC. Figure 3 is a representative reversed-phase HPLC chromatogram. Forty fractions were collected every 0.5 minute from 19.1 to 39.1 minutes (Figure 3(a), arrow). Fractions numbers $1-5$, numbers 6-8, numbers 26-30, numbers 31-35, and numbers 36-40 were pooled, respectively, since protein concentration of each fraction was apparently very low. Therefore, a total of 22 fractions were processed for SDS-PAGE analysis (Figure 3(b)).

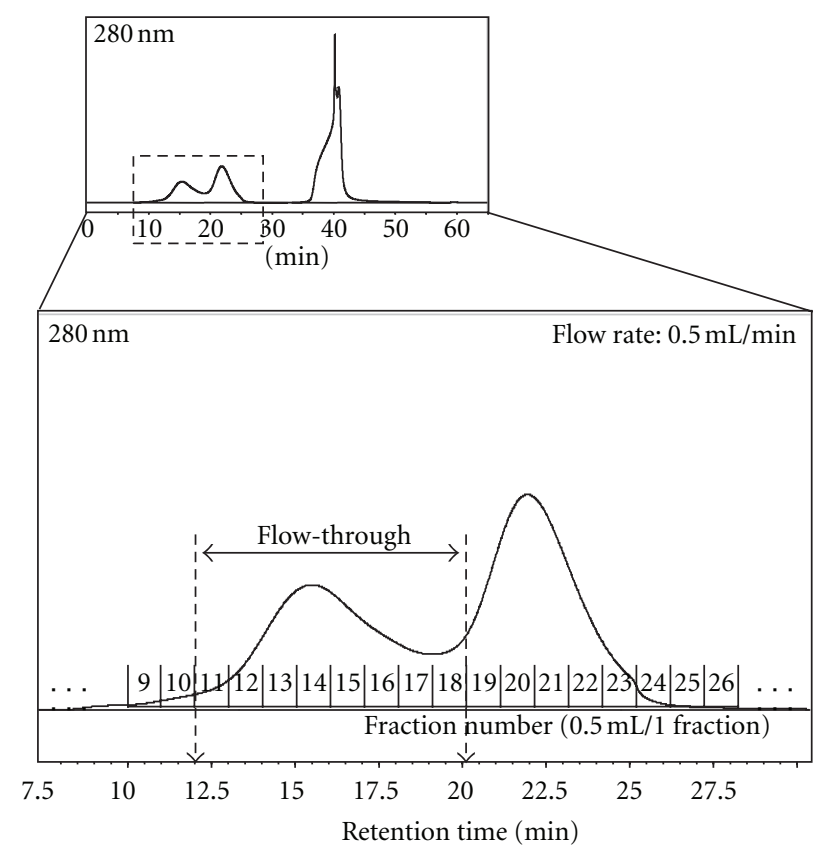

FIGURE 2: Representative chromatogram during removal of highly abundant serum proteins by an immunoaffinity column. $100 \mu \mathrm{L}$ of serum (diluted fivefold) was injected on the immunoaffinity column and was eluted $(0.5 \mathrm{~mL} / \mathrm{min})$ as described in the experimental procedures. Flow-through fractions (12.1-20.0 $\mathrm{min}$ ) were collected, and then a total of $4.0 \mathrm{~mL}$ fractions were concentrated to a volume of $80 \mu \mathrm{L}$ using Vivaspin 2 for reversed-phase HPLC fractionation.

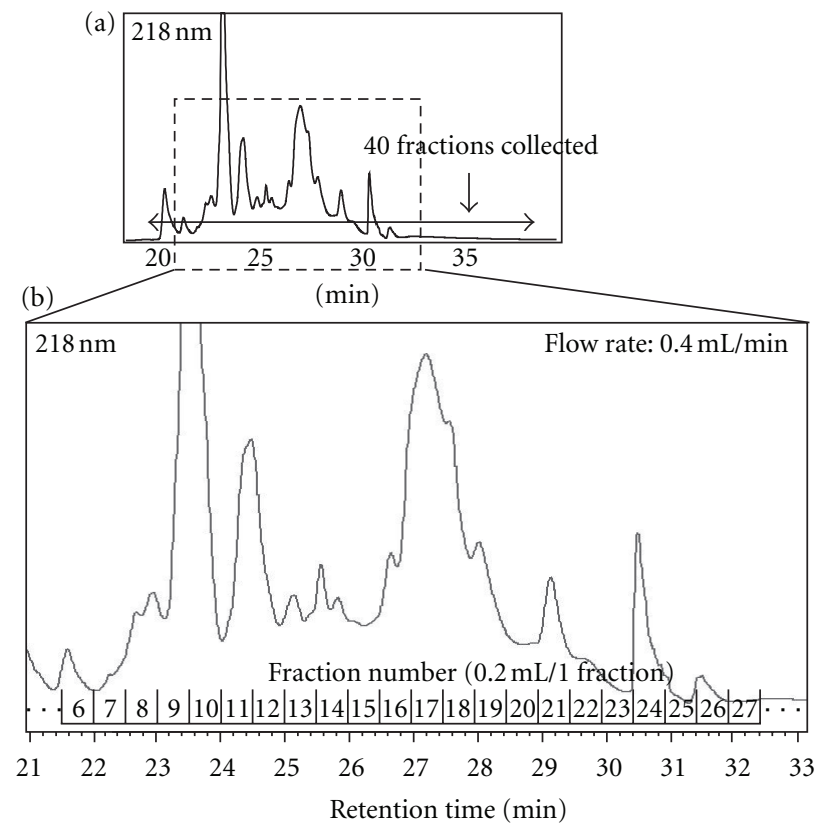

FIGURE 3: Representative chromatogram during fractionation by RP-HPLC of serum samples in which highly abundant proteins were immunodepleted. Concentrated immunodepleted samples were directly loaded onto the RP column and 40 fractions were collected every $0.5 \mathrm{~min}$ from 19.1 to $39.1 \mathrm{~min}$ ((a) arrow) as described in the experimental procedures. Among them, a total of 22 fractions were processed for SDS-PAGE analysis (b). 
TABLE 3: Upregulated proteins identified by LC-MS/MS in human HCC serum. Details are described in the experimental procedures.

\begin{tabular}{|c|c|c|c|c|c|}
\hline Protein name & Theoretical mass & Experimental mass & Score & Coverage & Queries matched \\
\hline Afamin precursor & 69024 & 90000 & 563 & $23 \%$ & 16 \\
\hline Alpha-1-antichymotrypsin & 48606 & 95000 & 118 & $4 \%$ & 2 \\
\hline Alpha-1-B-glycoprotein & 51908 & 95000 & 88 & $5 \%$ & 2 \\
\hline Alpha-1-microglobulin & 16531 & 230000 & 99 & $15 \%$ & 2 \\
\hline Alpha-2-macroglobulin & 163175 & 170000 & 2465 & $34 \%$ & 76 \\
\hline Angiotensinogen & 53122 & 55000 & 705 & $29 \%$ & 23 \\
\hline Antithrombin III & 49008 & 62000 & 389 & $24 \%$ & 9 \\
\hline Apolipoprotein A-IV & 45307 & 43000 & 639 & $30 \%$ & 12 \\
\hline Apolipoprotein B & 187126 & 140000 & 332 & $4 \%$ & 7 \\
\hline Apolipoprotein B-100 & 515077 & 140000 & 267 & $1 \%$ & 5 \\
\hline Apolipoprotein E & 36185 & 35000 & 832 & $44 \%$ & 33 \\
\hline Beta-actin & 41710 & 41000 & 226 & $17 \%$ & 4 \\
\hline $\mathrm{C} 1 \mathrm{q}$ & 26442 & 33000 & 113 & $11 \%$ & 2 \\
\hline C2 precursor & 83214 & 97000 & 557 & $15 \%$ & 14 \\
\hline $\mathrm{C} 3$ & 187046 & 180000 & 613 & $7 \%$ & 11 \\
\hline $\mathrm{C} 3 \mathrm{~b}$ & 103886 & 120000 & 2042 & $26 \%$ & 63 \\
\hline $\mathrm{C} 3 \mathrm{c}$ & 187046 & 33000 & 206 & $2 \%$ & 4 \\
\hline $\mathrm{C} 3 \mathrm{~d}$ & 120000 & 187046 & 153 & $1 \%$ & 3 \\
\hline C3, isoform CRA_a & 70000 & 143619 & 1636 & $28 \%$ & 64 \\
\hline $\mathrm{C} 4 \mathrm{~A}$ & 192741 & 24000 & 456 & $5 \%$ & 21 \\
\hline $\mathrm{C} 4 \mathrm{~B}$ & 40737 & 41000 & 138 & $7 \%$ & 2 \\
\hline C5 & 141723 & 120000 & 248 & $4 \%$ & 6 \\
\hline C6 & 104776 & 120000 & 96 & $4 \%$ & 2 \\
\hline $\mathrm{C} 7$ & 93449 & 95000 & 874 & $22 \%$ & 27 \\
\hline C8-alpha subunit & 65111 & 55000 & 109 & $3 \%$ & 2 \\
\hline C8-beta propeptide & 62008 & 70000 & 323 & $11 \%$ & 7 \\
\hline C8-gamma polypeptide & 22206 & 23000 & 352 & $40 \%$ & 15 \\
\hline C9 & 60359 & 70000 & 496 & $14 \%$ & 12 \\
\hline Complement receptor type 2 (Cr2) & 112900 & 160000 & 160 & $2 \%$ & 2 \\
\hline Component factor B & 85450 & 50000 & 163 & $4 \%$ & 3 \\
\hline Cr2-C3d complex & 34437 & 35000 & 151 & $10 \%$ & 3 \\
\hline Complement component $(3 \mathrm{~b} / 4 \mathrm{~b})$ receptor 1 & 61415 & 160000 & 102 & $4 \%$ & 2 \\
\hline Carbonic anhydrase I & 28852 & 25000 & 195 & $18 \%$ & 4 \\
\hline Carbonic anhydrase II & 29200 & 33000 & 208 & $18 \%$ & 4 \\
\hline Carboxypeptidase N Polypeptide 1 precursor & 52253 & 45000 & 147 & $11 \%$ & 3 \\
\hline Carboxypeptidase $\mathrm{N}$ precursor & 60578 & 97000 & 330 & $11 \%$ & 6 \\
\hline Cathepsin D preproprotein & 44524 & 49000 & 103 & $6 \%$ & 2 \\
\hline Cationic trypsinogen & 160000 & 120901 & 66 & - & 2 \\
\hline CD14 protein precursor & 40111 & 55000 & 365 & $21 \%$ & 8 \\
\hline Ceruloplasmin & 115398 & 140000 & 1520 & $27 \%$ & 44 \\
\hline Clusterin & 48772 & 39000 & 95 & $8 \%$ & 2 \\
\hline C-type lectin domain family 3 , member B & 22552 & 25000 & 243 & $24 \%$ & 6 \\
\hline Fibronectin precursor & 256529 & 230000 & 176 & $2 \%$ & 3 \\
\hline Galectin 3 binding protein & 65289 & 90000 & 177 & $3 \%$ & 3 \\
\hline Gelsolin & 85644 & 95000 & 474 & $15 \%$ & 11 \\
\hline Glutathione peroxidase 3 precursor & 25489 & 26000 & 167 & $16 \%$ & 4 \\
\hline Hemopexin precursor & 51512 & 50000 & 104 & $4 \%$ & 2 \\
\hline
\end{tabular}


TABle 3: Continued.

\begin{tabular}{|c|c|c|c|c|c|}
\hline Protein name & Theoretical mass & Experimental mass & Score & Coverage & Queries matched \\
\hline Heparin cofactor II & 57034 & 110000 & 372 & $21 \%$ & 8 \\
\hline Insulin-like growth factor binding protein & 65994 & 95000 & 176 & $6 \%$ & 3 \\
\hline Interalpha-trypsin inhibitor heavy chain $\mathrm{H} 1$ & 101339 & 230000 & 631 & $14 \%$ & 23 \\
\hline Interalpha-trypsin inhibitor heavy chain $\mathrm{H} 2$ & 106370 & 230000 & 862 & $15 \%$ & 28 \\
\hline ITI family heavy chain-related protein & 103321 & 120000 & 348 & $9 \%$ & 6 \\
\hline Kininogen 1 & 47853 & 120000 & 355 & $13 \%$ & 7 \\
\hline Lactate dehydrogenase B & 36615 & 35000 & 217 & $13 \%$ & 4 \\
\hline Leucine-rich alpha-2-glycoprotein 1 & 38154 & 50000 & 301 & $15 \%$ & 8 \\
\hline Lumican & 38375 & 70000 & 320 & $21 \%$ & 7 \\
\hline M130 antigen & 160000 & 120901 & 66 & $1 \%$ & 2 \\
\hline Multimerin 2 & 104352 & 20000 & 88 & $1 \%$ & 2 \\
\hline Pancreatic carboxypeptidase Al precursor & 47111 & 41000 & 92 & $5 \%$ & 2 \\
\hline Peptidoglycan recognition protein 2 precursor & 67927 & 70000 & 96 & $7 \%$ & 2 \\
\hline Pigment epithelial-differentiating factor (serpin-F1) & 46313 & 48000 & 946 & $50 \%$ & 22 \\
\hline Plasma protease $(\mathrm{C} 1)$ inhibitor precursor & 55147 & 90000 & 829 & $25 \%$ & 43 \\
\hline Prepro-plasma carboxypeptidase B & 48411 & 62000 & 100 & $6 \%$ & 2 \\
\hline Preserum amyloid $\mathrm{P}$ component & 25381 & 30000 & 362 & $26 \%$ & 13 \\
\hline Prolidase & 54348 & 55000 & 82 & $3 \%$ & 2 \\
\hline Proteasome alpha 4 subunit isoform 1 & 29465 & 33000 & 85 & $8 \%$ & 2 \\
\hline Sex-hormone-binding globulin & 43768 & 45000 & 391 & $28 \%$ & 10 \\
\hline Thyroxine-binding globulin precursor & 46295 & 55000 & 135 & $6 \%$ & 3 \\
\hline Trypsin inhibitor & 106647 & 55000 & 174 & $5 \%$ & 3 \\
\hline Vascular cell adhesion molecule 1 isoform & 81224 & 97000 & 133 & $3 \%$ & 2 \\
\hline Vitamin D binding protein & 51183 & 55000 & 669 & $21 \%$ & 17 \\
\hline Vitamin K-dependent protein S & 75074 & 95000 & 106 & $3 \%$ & 2 \\
\hline Vitronectin & 54308 & 10000 & 90 & $2 \%$ & 2 \\
\hline
\end{tabular}

3.3. SDS-PAGE Analysis. The representative silver-stained SDS-PAGE gel of a fraction (fraction number 13) obtained from seven HCC patients and five LC patients is shown in Figure 4(a).

Comparison of SDS-PAGE patterns of a total of 22 fractions revealed that intensities of 83 bands were greater in more than 3 cases of HCC than in those in LC cases. Among these, the intensities of 14 bands were increased in all the seven HCC patients. The representative examples are indicated by arrow heads.

3.4. Identification of Protein. To identify proteins, the expression of which was different between HCC and LC on silver stained gel, four HCC and four LC sera were fractionated and separated using SDS-PAGE again, and then gels were stained by CBB (Figure 4(b)). Because the sensitivity of the CBB stain is lower than of the silver stain, samples for identification were prepared from the beginning by repeating three courses of the procedures, from depletion of the major proteins to RP-HPLC fractionation. As a result, additional 71 bands were found to have altered intensity levels between the two groups on CBB gels. Thus, a total of 154 bands were considered as initial candidate bands. Forty-six out of these 154 bands, derived from more than two adjacent fractions, were not processed further. Finally, 108 bands were subjected to in-gel trypsin digestion: among them 73 proteins were identified by LC-MS/MS (Table 3 and Figure 5).

3.5. Western Blotting. Western blotting analysis could confirm that clusterin was overexpressed in the majority of HCC sera as compared with LC (Figure 6(a)).

Semiquantitative analysis of the results by TotaLab TL120 (Shimadzu Co., Ltd., Kyoto) revealed that the difference in serum clusterin levels between HCC and LC was statistically significant $(468211.38 \pm 103972.69$ versus $341686.90 \pm$ $123162.85, P=0.023$ ) as indicated in Figure 6(b).

3.6. Clusterin Concentration in Serum from HCC and LC Patients. To evaluate diagnostic values of serum clusterin levels for HCC diagnosis, we examined sera from 64 patients with HCC, 60 with LC, and 60 normal subjects. The concentration of clusterin (mean \pm SD) was $210.4 \pm 61.3 \mu \mathrm{g} / \mathrm{mL}$ for HCC, $170.9 \pm 50.0 \mu \mathrm{g} / \mathrm{mL}$ for LC, and $139.4 \pm 37.4 \mu \mathrm{g} / \mathrm{mL}$ for normal subjects and was significantly higher in HCC than in LC $(P<0.01$, Student's $t$-test $)$ and in normal subjects $(P<0.001)$ (Figure 7).

We set the cut-off value of clusterin at $230 \mu \mathrm{g} / \mathrm{mL}$ by calculating the mean $+2 \mathrm{SD}$ of healthy 60 samples. As a result, clusterin level above the value was found in 23 of 64 HCCs $(35.9 \%)$ and in 6 of 60 LCs (10.0\%). Furthermore, 


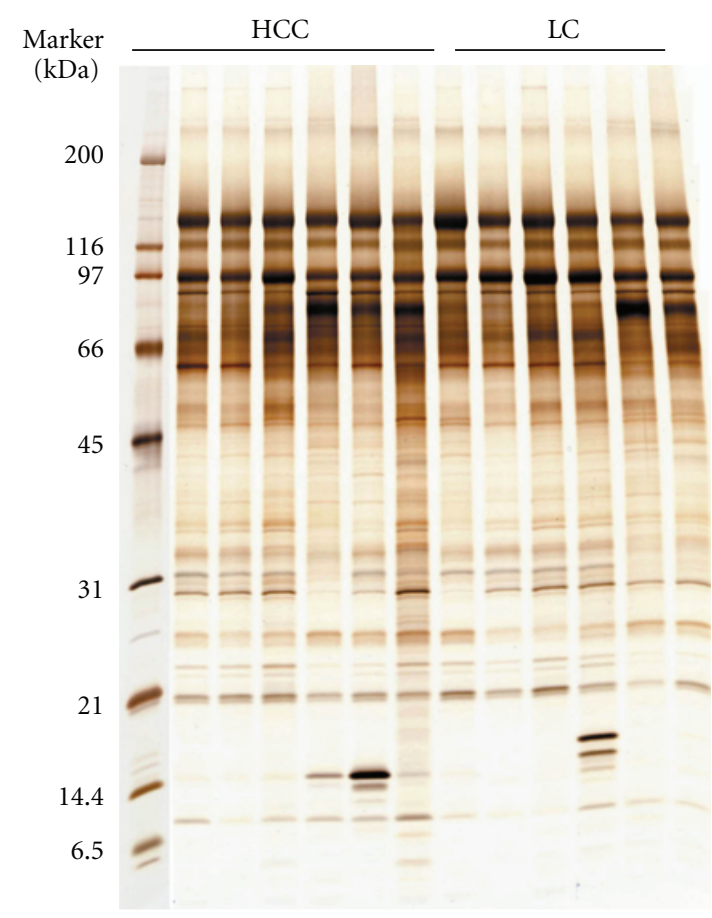

(a)

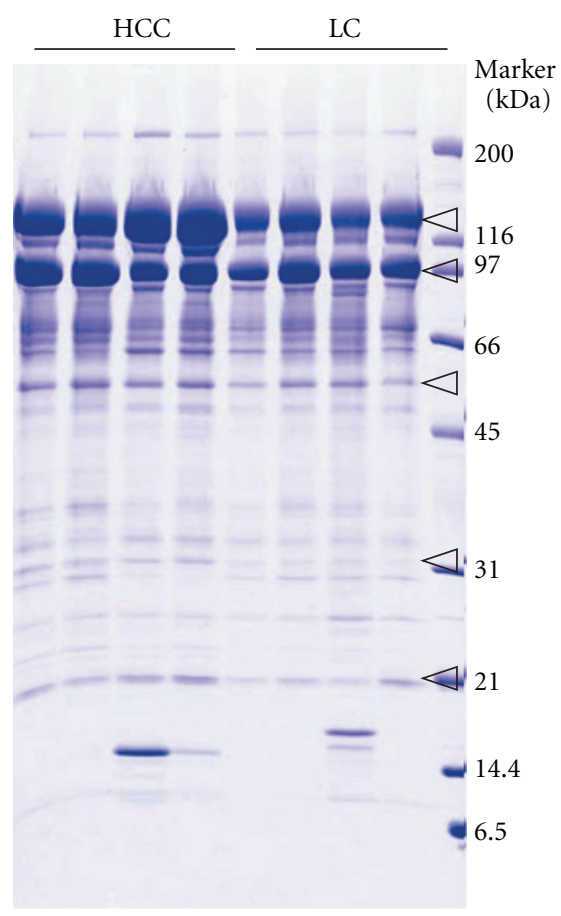

(b)

Figure 4: Representative SDS-PAGE pattern of immunodepleted serum sample after RP-HPLC fractionation (fraction number 13 ). $100 \mu \mathrm{L}$ of serum samples from seven HCC patients and five LC patients was immunodepleted and injected onto the column. Forty fractions were collected and dried, and among them 22 fractions were separated using 10-20\% SDS-PAGE. Each dried fraction was dissolved in $15 \mu \mathrm{L}$ of sample buffer and loaded onto the gel as described in the experimental procedures. Following electrophoresis, proteins were visualized by silver staining (a). For protein identification, $300 \mu \mathrm{L}$ of serum samples was prepared again and visualized by CBB staining (b). The intensities of 14 bands were increased in all the seven HCC patients. The representative examples are indicated by arrow heads.

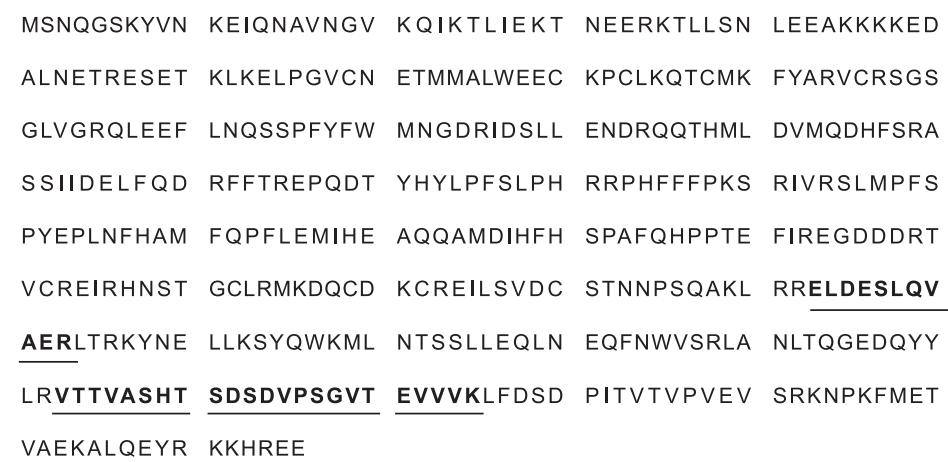

FIGURE 5: Identification of clusterin by LC-MS/MS. The amino acid sequence of clusterin is shown. Matched peptide sequences are printed in bold and underlined.

serum clusterin levels were above the cut-off value in 5 of 12 HCCs $(41.7 \%)$ in whom both serum AFP and PIVKA-II were within their cut-off values, suggesting that clusterin is complementary to the conventional two representative HCC tumor markers.

\section{Discussion}

The sequencing of the human genome has opened the door for comprehensive transcriptome and proteome analysis. Transcriptome analyses have revealed unique patterns for gene expression that are clinically informative. Messenger RNA abundances, however, are not necessarily predictive of corresponding protein abundances [42]. Since the detailed understanding of biological processes, both in healthy and pathological states, requires the direct study of relevant proteins, proteomics bridges the gap between the information coded in the genome sequence and cellular behavior. Therefore, proteomics is among the most promising technologies for the development of novel diagnostic tools.

Increasing number of studies has taken advantage of various proteomic technologies to discover and identify 


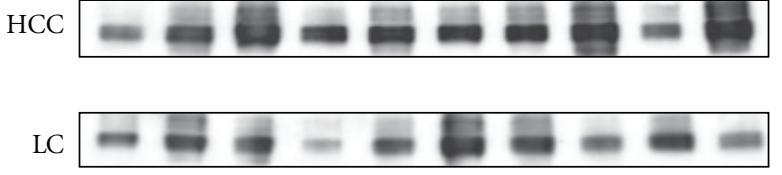

(a)

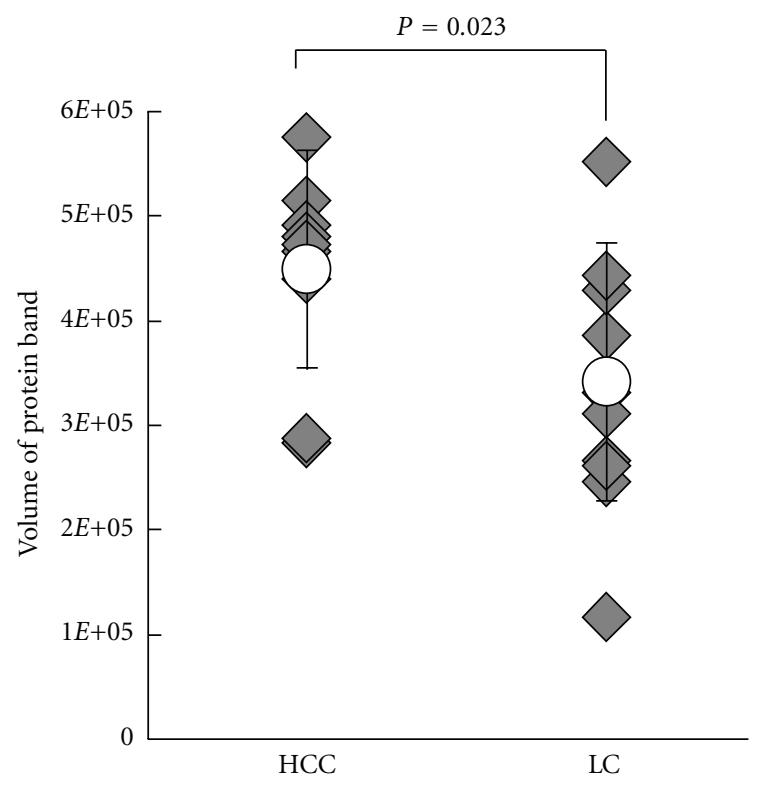

(b)

Figure 6: Western blot analysis of clusterin in sera from HCC and LC groups. (a) Immunoedpleted sera of the $5 \mathrm{HCC}$ and 5 LC SDS-PAGE cases and additional $5 \mathrm{HCC}$ and $5 \mathrm{LC}$ cases were separated by $10.0-12.0 \%$ SDS-PAGE and probed with anticlusterin. The expression levels are relatively higher in the HCC groups than LCs. (b) Differences in expression were analyzed by the Student's $t$-test. The expression levels of these proteins were upregulated significantly in HCC samples $(P=0.023)$. Rhombuses represent volumes of individual samples. Line indicates the range with the open circles indicating the mean values.

novel HCC markers. Clinical tissue samples have been the most extensively studied samples in HCC proteomic studies. Most studies compared protein expression profiles between tumor tissues and adjacent nontumor tissues using two dimensional electrophoresis (2DE) and two dimensional fluorescence difference gel electrophoresis (2D-DIGE).

Some studies used laser capture microdissection (LCM) in order to characterize isolated tumor cell populations from heterogeneous tissue sections. By combing LCM and 2DDIGE, Liang et al [43]. found that the protein profiles of well- and poorly differentiated HCC tissues are significantly different. Proteome analyses of tumor tissues should be a basis for HCC marker discovery and a number of proteins have been identified as candidate markers for HCC [4446]; none of them have been shown to be useful serum marker in a clinical setting. Among thousands of serum proteins and peptides, a few are so dominant that they may hamper the detection of other low abundance proteins or peptides. To overcome this problem, Feng et al. [47] took

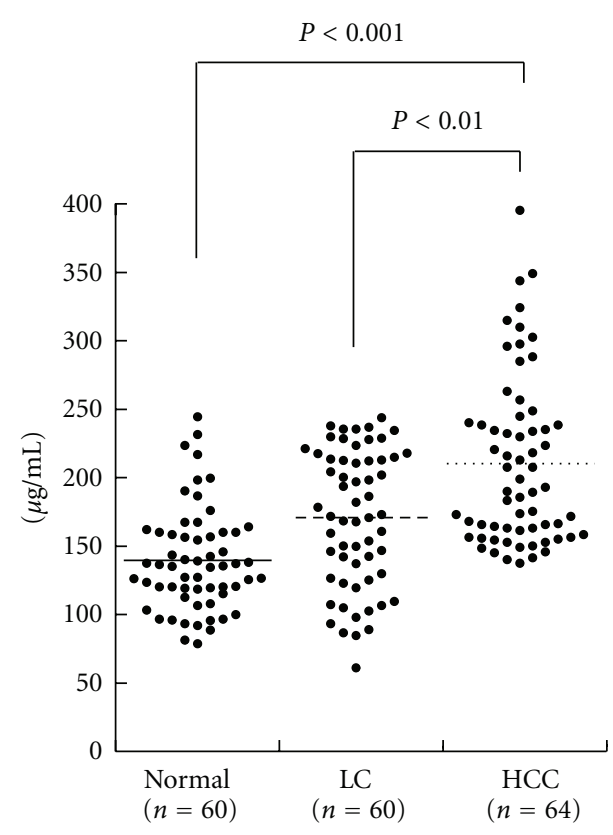

FIgURE 7: Concentration of clusterin in 64 patients with HCC, 60 patients with LC and 60 healthy individuals. Clusterin levels, quantified using ELISA, were significantly greater in HCC patients compared with LC, $(P<0.01)$ and normal subjects $(P<0.001)$.

a strategy to deplete abundant proteins such as albumin and immunoglobulin before analyses, followed by 2DE and MALDI-TOF MS/MS identification. They showed that heatshock-protein 27 could aid in the diagnosis of HCC.

In this study, three-step procedures including the immunodepletion of 12 abundant proteins were carried out to discover novel HCC markers. As a first step, serum samples were subjected to antibody-based immunoaffinity column that simultaneously removes 12 abundant serum proteins. The concentrated flow-through was then fractionated using reversed-phase HPLC. Proteins obtained in each HPLC fraction were further separated by SDS-PAGE. A total of 73 differentially expressed proteins were identified and among them clusterin was of particular interest as potential serum marker for HCC and differences in this expression in serum were confirmed by the western blotting.

Further validation using another set of serum sample set showed that clusterin level was significantly higher in HCC than in LC as determined by ELISA. It is notable that serum clusterin levels were elevated in 5 out of 12 HCC cases in which both AFP and PIVKA-II were within their cut-off values. As a result, combination assays of AFP PIVKA-II and clusterin could detect about $90 \%$ of HCC cases included in this study. These result suggested that clusterin could be HCC tumor marker complemenatary to AFP and PIVKA-II.

Clusterin, also known as apolipoprotein J (Apo J), sulfated glycoprotein 2, is a heterodimeric glycoprotein present in most animal tissues and body fluids [48]. This glycoprotein plays important roles in a variety of physiological processes including lipid transport [49], reproduction [50], tissue remodeling [51], and senescence [52]. 
Clusterin overexpression has been shown in various human malignancies including cancer of the breast [53], pancreas [54], and colon [55]. Kang et al. [56] demonstrated the overexpression of clusterin in HCC and suggested that its cytoplasmic overexpression might be a predictor of poor survival. Increased serum levels of clusterin in HCC patients had not been reported before.

In conclusion, the results of this study suggest that clusterin can be a supplementary serum biomarker for HCC. Exact mechanisms and pathophysiological significance for the upregulation of clusterin in HCC remain to be investigated. Furthermore, since the majority of HCC cases in Japan are related to $\mathrm{HCV}$, we focused on HCV-related HCC in the present study. It will be necessary to assess diagnostic values of serum clusterin levels in HBV-related cases as well.

\section{List of Abbreviations}

HCC: Hepatocellular carcinoma

AFP: $\quad$ Alpha-fetoprotein

DCP: Des-gamma-carboxy prothrombin

LC: $\quad$ Liver cirrhosis

SDS-PAGE: Sodium dodecyl sulfate polyacrylamide gel electrophoresis.

\section{References}

[1] J. O. Ogunbiyi, "Hepatocellular carcinoma in the developing world," Seminars in Oncology, vol. 28, no. 2, pp. 179-187, 2001.

[2] L. J. Lopez and J. A. Marrero, "Hepatocellular carcinoma," Current Opinion in Gastroenterology, vol. 20, no. 3, pp. 248253, 2004.

[3] S. Fujiyama, M. Tanaka, S. Maeda, H. Ashihara, R. Hirata, and K. Tomita, "Tumor markers in early diagnosis, follow-up and management of patients with hepatocellular carcinoma," Oncology, vol. 62, no. 1, pp. 57-63, 2002.

[4] J. Szklaruk, P. M. Silverman, and C. Charnsangavej, "Imaging in the diagnosis, staging, treatment, and surveillance of hepatocellular carcinoma," American Journal of Roentgenology, vol. 180, no. 2, pp. 441-454, 2003.

[5] P. J. Johnson, "The role of serum alpha-fetoprotein estimation in the diagnosis and management of hepatocellular carcinoma," Clinics in Liver Disease, vol. 5, no. 1, pp. 145-159, 2001.

[6] D. S. Chen, J. L. Sung, and J. C. Sheu, "Serum $\alpha$-fetoprotein in the early stage of human hepatocellular carcinoma," Gastroenterology, vol. 86, no. 6, pp. 1404-1409, 1984.

[7] F. Trevisani, S. De Notariis, G. Rapaccini et al., "Semiannual and annual surveillance of cirrhotic patients for hepatocellular carcinoma: effects on cancer stage and patient survival (Italian experience)," American Journal of Gastroenterology, vol. 97, no. 3, pp. 734-744, 2002.

[8] F. Nomura, K. Ohnishi, and Y. Tanabe, "Clinical features and prognosis of hepatocellular carcinoma with reference to serum alpha-fetoprotein levels: analysis of 606 patients," Cancer, vol. 64, no. 8, pp. 1700-1707, 1989.

[9] S. L. Tsai, G. T. Huang, P. M. Yang, J. C. Sheu, J. L. Sung, and D. S. Chen, "Plasma des- $\gamma$-carboxyprothrombin in the early stage of hepatocellular carcinoma," Hepatology, vol. 11, no. 3, pp. 481-488, 1990.

[10] K. Soga, T. Watanabe, K. Aikawa, M. Toshima, K. Shibasaki, and Y. Aoyagi, "Serum des-gamma-carboxyprothrombin level by a modified enzyme immunoassay method in hepatocellular carcinoma: clinical significance in small hepatocellular carcinoma," Hepato-Gastroenterology, vol. 45, no. 23, pp. 17371741, 1998.

[11] F. Nomura, M. Ishijima, K. Kuwa, N. Tanaka, T. Nakai, and K. Ohnishi, "Serum des-gamma-carboxy prothrombin levels determined by a new generation of sensitive immunoassays in patients with small-sized hepatocellular carcinoma," American Journal of Gastroenterology, vol. 94, no. 3, pp. 650-654, 1999.

[12] M. Capurro, I. R. Wanless, M. Sherman et al., "Glypican-3: a novel serum and histochemical marker for hepatocellular carcinoma," Gastroenterology, vol. 125, no. 1, pp. 89-97, 2003.

[13] Y. Hippo, K. Watanabe, A. Watanabe et al., "Identification of soluble NH2-terminal fragment of glypican-3 as a serological marker for early-stage hepatocellular carcinoma," Cancer Research, vol. 64, no. 7, pp. 2418-2423, 2004.

[14] T. Nakatsura, Y. Yoshitake, S. Senju et al., "Glypican-3, overexpressed specifically in human hepatocellular carcinoma, is a novel tumor marker," Biochemical and Biophysical Research Communications, vol. 306, no. 1, pp. 16-25, 2003.

[15] Y. Midorikawa, S. Ishikawa, H. Iwanari et al., "Glypican-3, overexpressed in hepatocellular carcinoma, modulates FGF2 and BMP-7 signaling," International Journal of Cancer, vol. 103, no. 4, pp. 455-465, 2003.

[16] Y. K. Sung, S. Y. Hwang, M. K. Park et al., "Glypican-3 is overexpressed in human hepatocellular carcinoma," Cancer Science, vol. 94, no. 3, pp. 259-262, 2003.

[17] Z. L. Lü, D. Z. Luo, and J. M. Wen, "Expression and significance of tumor-related genes in HCC," World Journal of Gastroenterology, vol. 11, no. 25, pp. 3850-3854, 2005.

[18] R. Cui, J. He, F. Zhang et al., "Diagnostic value of protein induced by vitamin $\mathrm{K}$ absence (PIVKAII) and hepatomaspecific band of serum gamma-glutamyl transferase (GGTII) as hepatocellular carcinoma markers complementary to $\alpha$ fetoprotein," British Journal of Cancer, vol. 88, no. 12, pp. 1878-1882, 2003.

[19] P. Tangkijvanich, P. Tosukhowong, P. Bunyongyod et al., "alpha-L-fucosidase as a serum marker of hepatocellular carcinoma in Thailand," Southeast Asian Journal of Tropical Medicine and Public Health, vol. 30, no. 1, pp. 110-114, 1999.

[20] H. Ishizuka, T. Nakayama, S. Matsuoka et al., "Prediction of the development of hepato-cellular-carcinoma in patients with liver cirrhosis by the serial determinations of serum alpha-L-fucosidase activity," Internal Medicine, vol. 38, no. 12, pp. 927-931, 1999.

[21] Z. Liu, L. Yan, T. Xiang, L. Jiang, and B. Yang, "Expression of vascular endothelial growth factor and matrix metalloproteinase- 2 correlates with the invasion and metastasis of hepatocellular carcinoma," Sheng Wu Yi Xue Gong Cheng Xue Za Zhi, vol. 20, no. 2, pp. 249-254, 2003.

[22] G. W. Huang, L. Y. Yang, and W. Q. Lu, "Expression of hypoxia-inducible factor $1 \alpha$ and vascular endothelial growth factor in hepatocellular carcinoma: impact on neovascularization and survival," World Journal of Gastroenterology, vol. 11, no. 11, pp. 1705-1708, 2005.

[23] S. J. Kim, I. K. Choi, K. H. Park et al., "Serum vascular endothelial growth factor per platelet count in hepatocellular carcinoma: correlations with clinical parameters and survival," Japanese Journal of Clinical Oncology, vol. 34, no. 4, pp. 184190, 2004.

[24] B. C. Song, Y. H. Chung, J. A. Kim et al., “Transforming growth factor- $\beta 1$ as a useful serologic marker of small hepatocellular carcinoma," Cancer, vol. 94, no. 1, pp. 175-180, 2002. 
[25] R. Sacco, D. Leuci, C. Tortorella, G. Fiore, F. Marinosci, and S. Antonaci, "Transforming growth factor $\beta 1$ and soluble Fas serum levels in hepatocellular carcinoma," Cytokine, vol. 12, no. 6, pp. 811-814, 2000.

[26] X. P. Chen, H. Zhao, and X. P. Zhao, "Alternation of AFPmRNA level detected in blood circulation during liver resection for HCC and its significance," World Journal of Gastroenterology, vol. 8, no. 5, pp. 818-821, 2002.

[27] X. Ding, L. Y. Yang, G. W. Huang et al., "Role of AFP mRNA expression in peripheral blood as a predictor for postsurgical recurrence of hepatocellular carcinoma: a systematic review and meta-analysis," World Journal of Gastroenterology, vol. 11, no. 17, pp. 2656-2661, 2005.

[28] N. Miura, Y. Maeda, T. Kanbe et al., "Serum human telomerase reverse transcriptase messenger RNA as a novel tumor marker for hepatocellular carcinoma," Clinical Cancer Research, vol. 11, no. 9, pp. 3205-3209, 2005.

[29] N. Miura, G. Shiota, T. Nakagawa et al., "Sensitive detection of human telomerase reverse transcriptase mRNA in the serum of patients with hepatocellular carcinoma," Oncology, vol. 64, no. 4, pp. 430-434, 2003.

[30] T. Hutchens and T. T. Yip, "New desorption strategies for the mass spectrometric analysis of macromolecules," Rapid Communications in Mass Spectrometryvol, vol. 7, pp. 576-580, 1993.

[31] F. Nomura, T. Tomonaga, K. Sogawa et al., "Identification of novel and downregulated biomarkers for alcoholism by surface enhanced laser desorption/ionization-mass spectrometry," Proteomics, vol. 4, no. 4, pp. 1187-1194, 2004.

[32] K. Sogawa, S. Itoga, T. Tomonaga, and F. Nomura, "Diagnostic values of surface-enhanced laser desorption/ionization technology for screening of habitual drinkers," Alcoholism, vol. 31, supplement s1, pp. S22-S26, 2007.

[33] V. Paradis, F. Degos, D. Dargère et al., "Identification of a new marker of hepatocellular carcinoma by serum protein profiling of patients with chronic liver diseases," Hepatology, vol. 41, no. 1, pp. 40-47, 2005.

[34] S. Kanmura, H. Uto, K. Kusumoto et al., "Early diagnostic potential for hepatocellular carcinoma using the SELDI ProteinChip system," Hepatology, vol. 45, no. 4, pp. 948-956, 2007.

[35] N. L. Anderson and N. G. Anderson, "The human plasma proteome: history, character, and diagnostic prospects," Molecular \& Cellular Proteomics, vol. 1, no. 11, pp. 845-867, 2002.

[36] N. Hattori, S. Oda, T. Sadahiro et al., "YKL-40 identified by proteomic analysis as a biomarker of sepsis," Shock, vol. 32, no. 4, pp. 393-400, 2009.

[37] K. Sogawa, Y. Kodera, M. Satoh et al., "Increased serum levels of pigment epithelium-derived factor by excessive alcohol consumption-detection and identification by a three-step serum proteome analysis," Alcoholism, vol. 35, no. 2, pp. 211217, 2011.

[38] M. Kadowaki, T. Sangai, T. Nagashima et al., "Identification of vitronectin as a novel serum marker for early breast cancer detection using a new proteomic approach," Journal of Cancer Research and Clinical Oncology, vol. 137, no. 7, pp. 1105-1115, 2011.

[39] M. Abulaizi, T. Tomonaga, M. Satoh et al., "The application of a three-step proteome analysis for identification of new biomarkers of pancreatic cancer," International Journal of Proteomics, vol. 2011, Article ID 628787, 13 pages, 2011.
[40] H. Umemura, M. Nezu, Y. Kodera et al., "Effects of the time intervals between venipuncture and serum preparation for serum peptidome analysis by matrix-assisted laser desorption/ionization time-of-flight mass spectrometry," Clinica Chimica Acta, vol. 406, no. 1-2, pp. 179-180, 2009.

[41] U. K. Laemmli, "Cleavage of structural proteins during the assembly of the head of bacteriophage T4," Nature, vol. 227, no. 5259, pp. 680-685, 1970.

[42] L. Anderson and J. Seilhamer, "A comparison of selected mRNA and protein abundances in human liver," Electrophoresis, vol. 18, no. 3-4, pp. 533-537, 1997.

[43] C. R. M. Y. Liang, C. K. Leow, J. C. H. Neo et al., "Proteome analysis of human hepatocellular carcinoma tissues by two-dimensional difference gel electrophoresis and mass spectrometry," Proteomics, vol. 5, no. 8, pp. 2258-2271, 2005.

[44] J. Kim, S. H. Kim, S. U. Lee et al., "Proteome analysis of human liver tumor tissue by two-dimensional gel electrophoresis and matrix assisted laser desorption/ionization-mass spectrometry for identification of disease-related proteins," Electrophoresis, vol. 23, no. 24, pp. 4142-4156, 2002.

[45] I. N. Lee, C. H. Chen, J. C. Sheu et al., "Identification of human hepatocellular carcinoma-related biomarkers by twodimensional difference gel electrophoresis and mass spectrometry," Journal of Proteome Research, vol. 4, no. 6, pp. 20622069, 2005.

[46] O. L. Seung, S. J. Park, W. Kim et al., "Proteome analysis of hepatocellular carcinoma," Biochemical and Biophysical Research Communications, vol. 291, no. 4, pp. 1031-1037, 2002.

[47] J. T. Feng, Y. K. Liu, H. Y. Song et al., "Heat-shock protein 27: a potential biomarker for hepatocellular carcinoma identified by serum proteome analysis," Proteomics, vol. 5, no. 17, pp. 4581-4588, 2005.

[48] O. Blaschuk, K. Burdzy, and I. B. Fritz, "Purification and characterization of a cell-aggregating factor (clusterin), the major glycoprotein in ram rete testis fluid," The Journal of Biological Chemistry, vol. 258, no. 12, pp. 7714-7720, 1983.

[49] H. V. De Silva, W. D. Stuart, C. R. Duvic et al., "A 70-kDa apolipoprotein designated ApoJ is a marker for subclasses of human plasma high density lipoproteins," The Journal of Biological Chemistry, vol. 265, no. 22, pp. 13240-13247, 1990.

[50] I. P. Trougakos and E. S. Gonos, "Clusterin/Apolipoprotein $\mathrm{J}$ in human aging and cancer," International Journal of Biochemistry and Cell Biology, vol. 34, no. 11, pp. 1430-1448, 2002.

[51] T. L. Brown, B. C. Moulton, V. V. Baker, J. Mira, and J. A. K. Harmony, "Expression of apolipoprotein $\mathrm{J}$ in the uterus is associated with tissue remodeling," Biology of Reproduction, vol. 52, no. 5, pp. 1038-1049, 1995.

[52] C. Petropoulou, I. P. Trougakos, E. Kolettas, O. Toussaint, and E. S. Gonos, "Clusterin/apolipoprotein J is a novel biomarker of cellular senescence that does not affect the proliferative capacity of human diploid fibroblasts," FEBS Letters, vol. 509, no. 2, pp. 287-297, 2001.

[53] M. Redondo, E. Villar, J. Torres-Munoz, T. Tellez, M. Morell, and C. K. Petito, "Overexpression of clusterin in human breast carcinoma," American Journal of Pathology, vol. 157, no. 2, pp. 393-399, 2000.

[54] M. J. Xie, Y. Motoo, S. B. Su et al., "Expression of clusterin in human pancreatic cancer," Pancreas, vol. 25, no. 3, pp. 234$238,2002$. 
[55] X. Chen, R. B. Halberg, W. M. Ehrhardt, J. Torrealba, and W. F. Dove, "Clusterin as a biomarker in murine and human intestinal neoplasia," Proceedings of the National Academy of Sciences of the United States of America, vol. 100, no. 16, pp. 9530-9535, 2003.

[56] Y. K. Kang, S. W. Hong, H. Lee, and W. H. Kim, "Overexpression of clusterin in human hepatocellular carcinoma," Human Pathology, vol. 35, no. 11, pp. 1340-1346, 2004. 

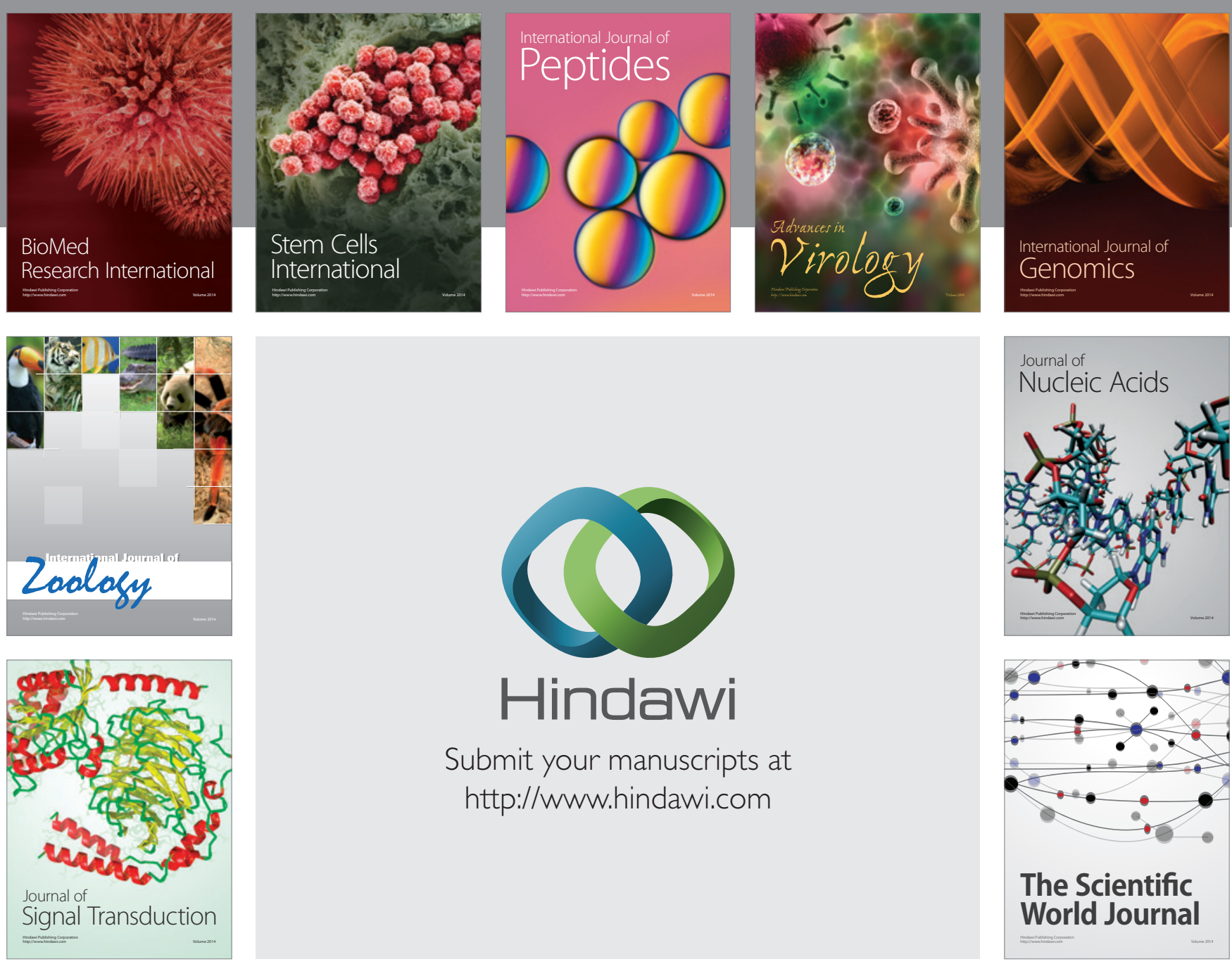

Submit your manuscripts at

http://www.hindawi.com
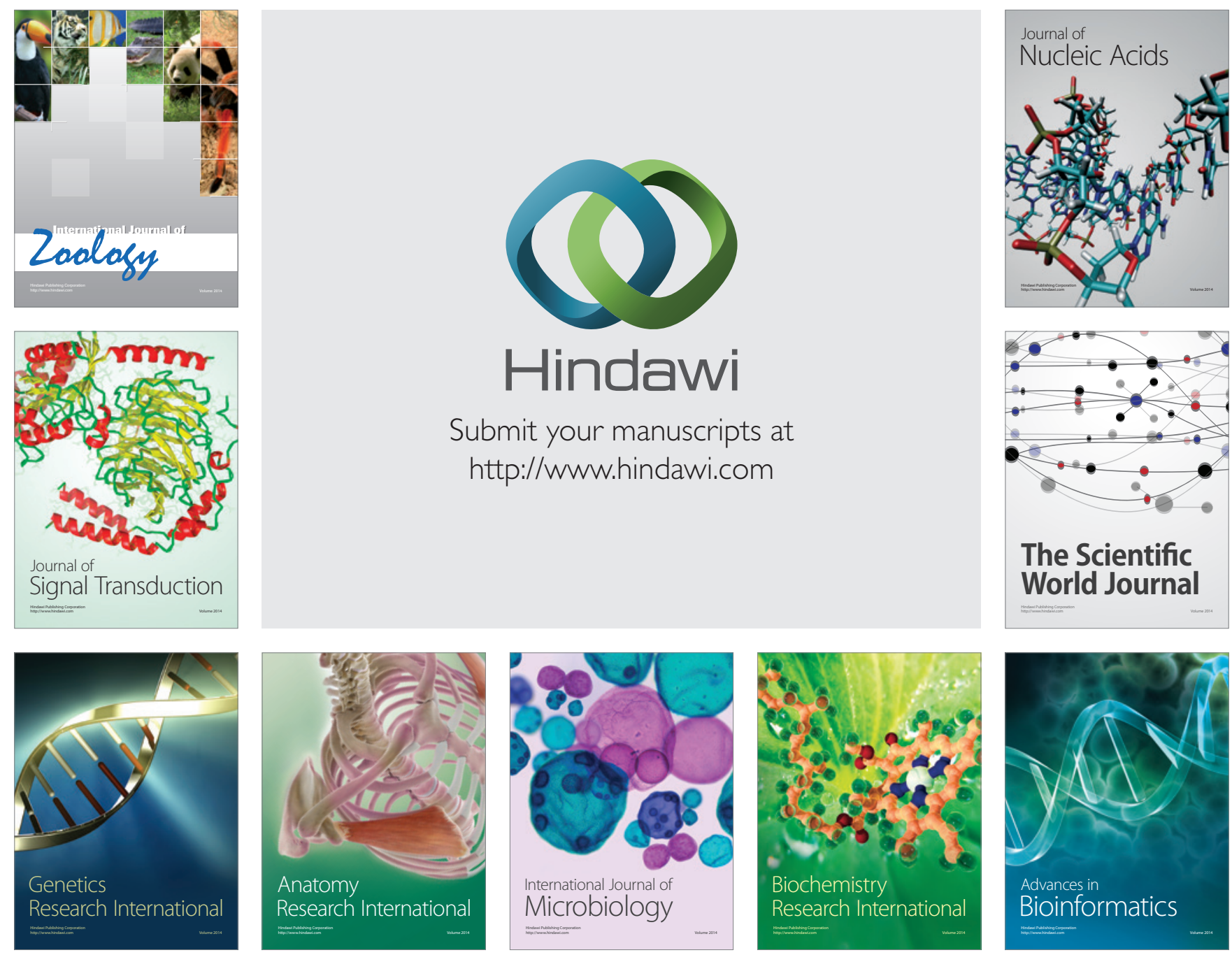

The Scientific World Journal
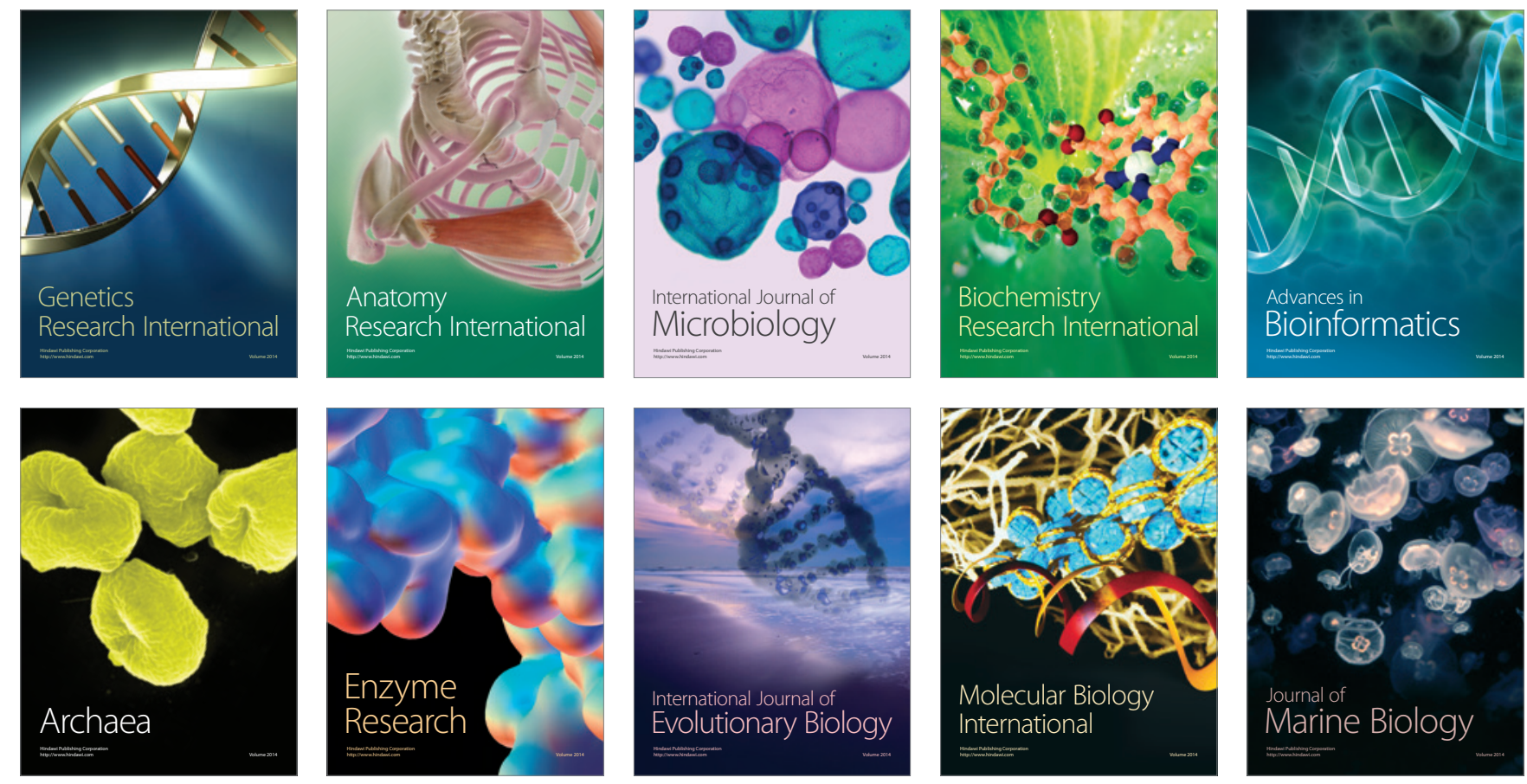